\title{
Erratum zu: Lehrerprofessionalität im Bereich der politischen Bildung
}

\section{Erratum zu:}

(C) Springer Fachmedien Wiesbaden GmbH 2018

B. Reichhart, Lehrerprofessionalität im Bereich der politischen Bildung, Empirische Forschung in den gesellschaftswissenschaftlichen Fachdidaktiken, https://doi.org/10.1007/978-3-658-19708-7_12

Im ursprünglichen Werk wurde auf Seite 34 verlagsseitig fälschlicherweise eine fehlerhafte Abbildung verwendet. Dieser Fehler wurde nun behoben.

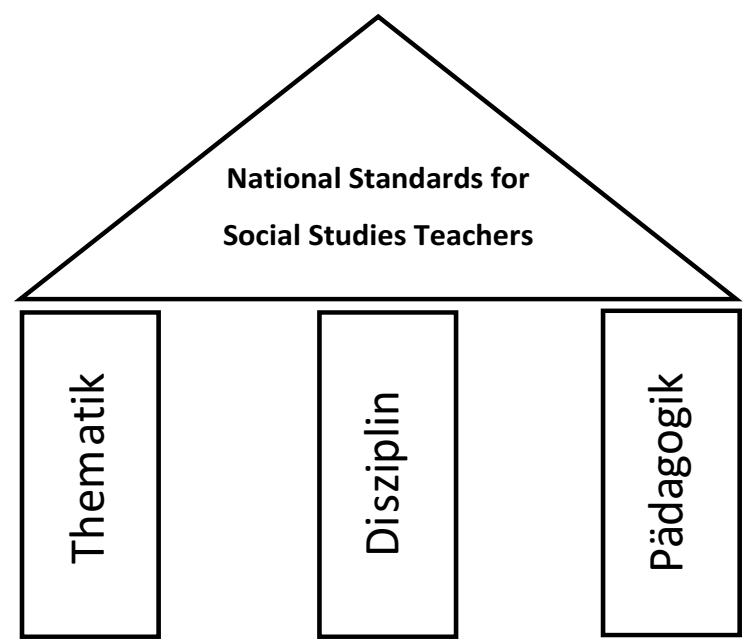

Abb. 3 National Standards for Social Studies Teachers (vgl. NCSS, 2006, S. 13f.)

Die aktualisierte Originalversion des Kapitels kann hier abgerufen werden https://doi.org/10.1007/978-3-658-19708-7_5

(C) Springer Fachmedien Wiesbaden GmbH 2018

B. Reichhart, Lehrerprofessionalität im Bereich der politischen Bildung, Empirische Forschung in den gesellschaftswissenschaftlichen Fachdidaktiken, https://doi.org/10.1007/978-3-658-19708-7_12 